\title{
Unexpected genetic diversity of Mycoplasma agalactiae caprine isolates from an endemic geographically restricted area of Spain
}

Christian De la Fe ${ }^{1 *}$, Joaquín Amores ${ }^{1}$, Florence Tardy ${ }^{2}$, Eveline Sagne ${ }^{4,3}$, Laurent-Xavier Nouvel ${ }^{4,3}$ and Christine Citti $i^{3,4}$

\begin{abstract}
Background: The genetic diversity of Mycoplasma agalactiae (MA) isolates collected in Spain from goats in an area with contagious agalactia (CA) was assessed using a set of validated and new molecular typing methods. Validated methods included pulsed field gel electrophoresis (PFGE), variable number of tandem repeats (VNTR) typing, and Southern blot hybridization using a set of MA DNA probes, including those for typing the vpma genes repertoire. New approaches were based on PCR and targeted genomic regions that diverged between strains as defined by in silico genomic comparisons of sequenced MA genomes.

Results: Overall, the data showed that all typing tools yielded consistent results, with the VNTR analyses being the most rapid method to differentiate the MA isolates with a discriminatory ability comparable to that of PFGE and of a set of new PCR assays. All molecular typing approaches indicated that the Spanish isolates from the endemic area in Murcia were very diverse, with different clonal isolates probably restricted to separate, but geographically close, local areas.

Conclusions: The important genetic diversity of MA observed in infected goats from Spain contrasts with the overall homogeneity of the genomic background encountered in MA from sheep with CA in Southern France or Italy, suggesting that assessment of the disease status in endemic areas may require different approaches in sheep and in goats. A number of congruent sub-typing tools are now available for the differentiation of caprine isolates with comparable discriminatory powers.
\end{abstract}

Keywords: Mycoplasma agalactiae, Molecular typing, Contagious agalactia, Goats

\section{Background}

Contagious agalactia (CA) is a disease of small ruminants associated with several clinical signs, including mastitis, arthritis, keratoconjunctivitis, pneumonia and septicaemia. CA is listed by the World Organization for Animal Health and is responsible for significant economic loss, with its severity and expression being dependent on several factors, including the host species, the aetiological agent, the production system and the environmental conditions [1-4]. In this context, defining the sanitary status of herds or regions with respect to

\footnotetext{
* Correspondence: cdelafe@um.es

${ }^{1}$ Departamento de Sanidad Animal, Facultad de Veterinaria, Universidad de Murcia, Campus de Espinardo s/n, 30100 Murcia, Spain

Full list of author information is available at the end of the article
}

CA is essential, but also very challenging. Three statuses are currently recognised: disease-free areas, areas with sporadic acute outbreaks and endemic areas, where infection is widespread although not always acute $[1,4]$. In CA endemic regions animals typically have no to transitory clinical sign and there are many asymptomatic auricular carriers [5-8]. Preventive and therapeutic strategies remain very inefficient in the control of CA, most likely because of both pathogen-specific features and the lack of epidemiological data. Thus far management strategies have been the most satisfactory method for controlling this disease [4].

Mycoplasma species responsible for CA include Mycoplasma mycoides subspecies capri (Mmc), Mycoplasma capricolum subspecies capricolum (Mcc) and Mycoplasma

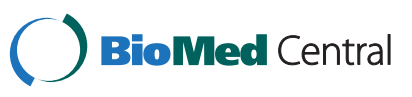


Table 1 Molecular typing of the Mycoplasma agalactiae isolates and strains

\begin{tabular}{|c|c|c|c|c|c|c|c|c|c|c|c|c|c|c|c|c|c|}
\hline Isolate & Source & Origin-Date $^{a}$ & $\begin{array}{l}\text { PFGE } \\
\text { profile }^{b}\end{array}$ & $\begin{array}{l}\text { VNTR } \\
5^{c} \\
\end{array}$ & $\begin{array}{l}\text { VNTR } \\
14^{c} \\
\end{array}$ & $\begin{array}{l}\text { VNTR } \\
17^{c} \\
\end{array}$ & $\begin{array}{l}\text { VNTR } \\
19^{c} \\
\end{array}$ & $\begin{array}{l}\text { All VNTR } \\
\text { profiles }^{d}\end{array}$ & $\begin{array}{l}\text { vpma } \\
\text { profiles }\end{array}$ & $\begin{array}{l}\text { AGA/BOV } \\
\text { profile }^{f}\end{array}$ & $\begin{array}{l}\text { PCR } \\
\text { control set }\end{array}$ & $\begin{array}{l}\text { PCR } \\
\text { set } 1^{g}\end{array}$ & $\begin{array}{l}\text { PCR } \\
\text { set } 2^{g}\end{array}$ & $\begin{array}{l}\text { PCR } \\
\text { set } 3\end{array}$ & $\begin{array}{l}\text { PCR } \\
\text { set } 4\end{array}$ & $\begin{array}{l}\text { PCR } \\
\text { set } 5\end{array}$ & $\begin{array}{l}\text { PCR } \\
\text { set } 6 \\
\end{array}$ \\
\hline PG2 & Unk & Unk-1952 & A & $2.1^{*}$ & $2^{*}$ & $2.6^{*}$ & $4.9^{*}$ & TR1 & VP1a & AGB1 & + & PG2 & PG2 & - & - & - & + \\
\hline AG30 & BTM & YE-2000 & A & 2.1 & 2 & $4.4^{*}$ & 4.9 & TR2 & VP2 & AGB1 & + & PG2 & PG2 & - & - & - & + \\
\hline AG33 & BTM & YE-2000 & $\mathrm{A}$ & 2.1 & 2 & 4.4 & 4.9 & TR2 & VP2 & AGB1 & + & PG2 & PG2 & - & - & - & + \\
\hline AG35 & BTM & YE-2000 & $\mathrm{A}$ & 2.1 & 2 & 4.4 & 4.9 & TR2 & VP2 & AGB1 & + & PG2 & PG2 & - & - & - & + \\
\hline AG28 & BTM & YE-2000 & A & $2.1^{*}$ & 2 & 4.4 & 4.9 & TR2 & VP2 & AGB1 & + & PG2 & PG2 & - & - & - & + \\
\hline AG18 & Mastitis & MA-2008 & $\mathrm{A} 1$ & 2.1 & 2 & 4.4 & 4.9 & TR2 & VP1b & AGB1 & + & PG2 & PG2 & - & - & - & + \\
\hline$\overline{A G 4}$ & BTM & LO-2009 & $A$ & 2.1 & $2^{*}$ & 4.4 & 4.9 & TR2 & VP2 & AGB1 & + & PG2 & $P G 2$ & - & - & + & + \\
\hline AG13 & Semen & LO-2008 & $C$ & $2.1^{*}$ & 0 & 0 & 4.9 & TR3 & VP3a & AGB2 & + & PG2 & $P G 2$ & - & + & + & - \\
\hline AG14 & Semen & LO-2008 & C & 2.1 & 0 & 0 & $4.9^{*}$ & TR3 & VP3b & AGB2 & + & PG2 & PG2 & - & + & + & - \\
\hline AG26 & BTM & $\mathrm{JU}-2000$ & $B$ & 2.1 & 0 & 6.3 & 4.9 & TR4 & VP5 & AGB3 & + & PG2 & 5632 & + & + & + & - \\
\hline AG27 & BTM & $\mathrm{JU}-2000$ & $B$ & 2.1 & 0 & 6.3 & 4.9 & TR4 & VP5 & AGB3 & + & PG2 & 5632 & + & + & + & - \\
\hline AG29 & BTM & $\mathrm{JU}-2000$ & B & 2.1 & 0 & 6.3 & 4.9 & TR4 & VP5 & AGB3 & + & PG2 & 5632 & + & + & + & - \\
\hline AG32 & BTM & JU-2000 & B & 2.1 & 0 & $6.3^{*}$ & 4.9 & TR4 & VP5 & AGB3 & + & PG2 & 5632 & + & + & + & - \\
\hline AG34 & BTM & $\mathrm{JU}-2000$ & $B$ & 2.1 & 0 & 6.3 & 4.9 & TR4 & VP5 & AGB3 & + & PG2 & 5632 & + & + & + & - \\
\hline 5632 & Arthritis & Unk-<1991 & $\mathrm{D}$ & 2.1 & 0 & $6.4^{*}$ & 4.9 & TR5 & VP7 & AGB4 & + & 5632 & 5632 & + & + & + & - \\
\hline
\end{tabular}

${ }^{a}$ Code for the geographical origin of the isolate and the year of isolation: YE: Yecla, MA: Málaga, LO: Lorca, MU: Murcia, JU: Jumilla. The symbol < is used when the exact year is unknown (Unk).

${ }^{\mathrm{b}}$ Profiles as defined by PFGE analyses.

'Number of repeats based on the consensus sequence determined for each VNTR. * indicates VNTR for which the PCR product was sequenced.

dProfiles as defined by VNTR analyses based on data a combination of data generated with each VNTR.

evpma profiles defined based on data in Additional file 2: Table $\mathbf{S 2}$.

${ }^{\mathrm{f}} \mathrm{AGA}-\mathrm{BOV}$ profiles defined based on data in Additional file 2: Table S2.

9PG2: data obtained were identical to those obtained with strain PG2; 5632: data obtained were identical to those obtained with strain 5632. BTM Bulk tank milk. 
putrefaciens, from the spiroplasma phylogenetic group, and Mycoplasma agalactiae (MA), from the hominis phylogenetic group, with this latter species being designated the stricto sensu aetiological agent of CA [1,4]. Interestingly, $\mathrm{CA}$ in sheep is often associated only with MA, while the situation can be more complex in goats, in which CA is commonly associated with both MA and mycoplasmas of the "mycoides" cluster $[1,4,8]$.

The complex clinical situation described above requires tools capable of exploring the dynamics of infection in order to set up management strategies. Thus far, several typing techniques have been used to characterize CA agents, including analysis of variable numbers of tandem repeats (VNTR) [9], multilocus sequence typing (MLST) [10], Southern blots using DNA probes [11], insertion sequence (IS) typing $[8,12]$ and pulsed field gel electrophoresis (PFGE) $[8,13,14]$. However, their capacity to answer epidemiological questions is variable. For instance, PFGE is very useful when comparing an asymptomatic goat herd infected with multiple polymorphic $M m c$ strains to an outbreak in which one unique clone was predominant [8]. However, application of the same technique to MA isolates in another situation resulted in poor discrimination and was not informative about the strain circulation [13].

A number of studies has been conducted to characterize and compare isolates of MA from outbreaks of CA. These have generally focused on sets of isolates from various geographical origins $[11,12,14]$, but the reports have provided few details about the status of the herds with respect to infection, the type of herds or the animals from which the isolates were collected $[9,10]$. In addition, typing analyses that have been performed in well-documented epidemiological contexts have mainly examined CA in sheep $[13,15]$ leaving the situation in goats unexplored. This gap is surprising, as CA in goats can be of considerable economical importance, and also because the two currently available genomic sequences $[16,17]$ from which many typing tools were derived, are both from strains with a caprine origin.

The present study is, to our knowledge, the first to conduct a detailed characterization of potential molecular differences between caprine MA isolates collected in a geographically restricted area (Murcia, Spain). This area hosts a native goat breed, the Murciano Granadina, and uses a semi-intensive production system based around a single insemination centre. Although this limits the entry of animals from other regions, Murcia is known to have had endemic CA for many years [18,19]. This has raised the question of the mode of dissemination and the origins of the agent responsible for CA in this area.

The purpose of the present study was to assess the relevance of typing approaches already validated on large and diverse strain collections (PFGE, VNTR, IS-typing) to

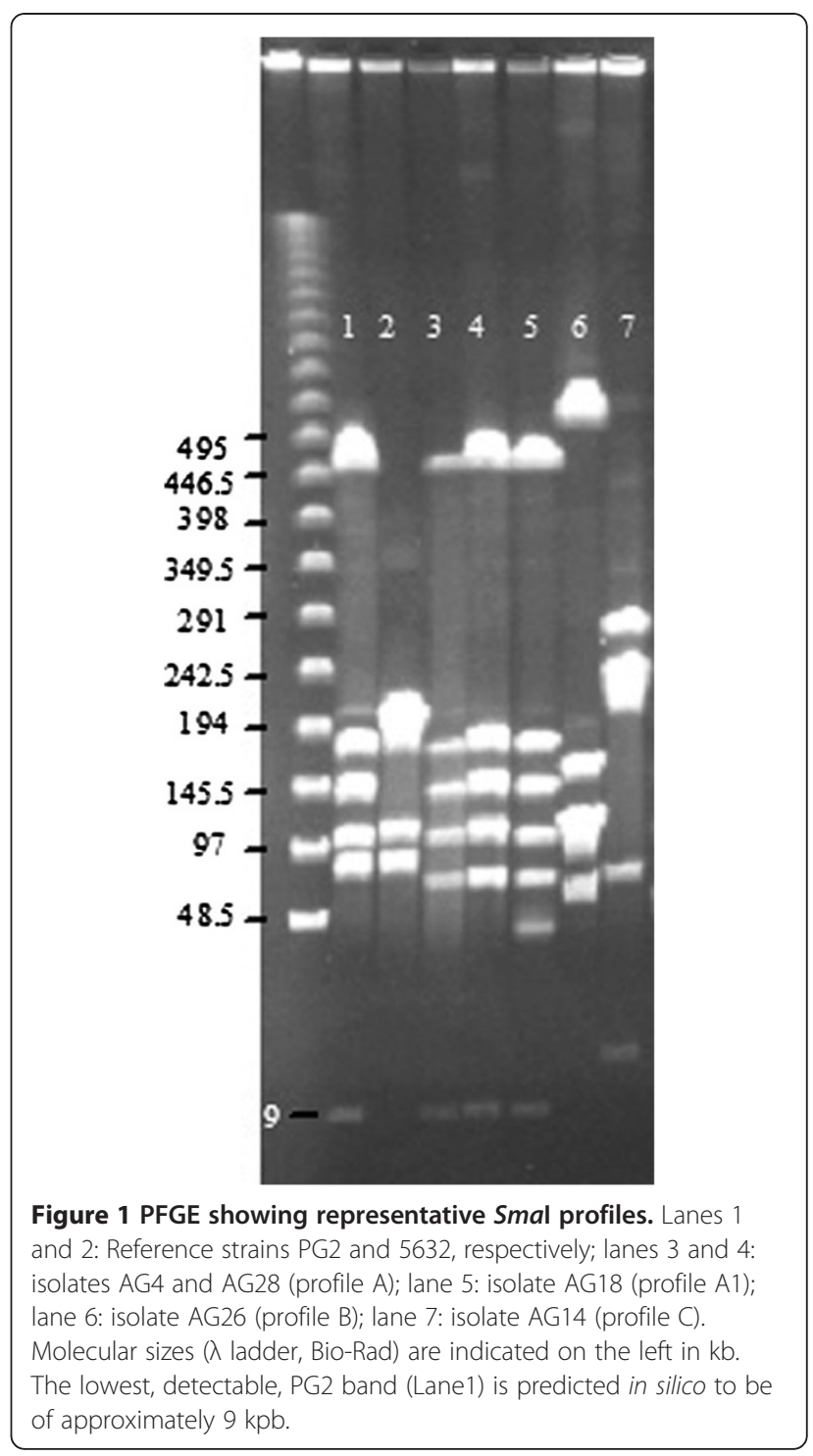

discriminate a limited number of caprine isolates from a common geographical origin (Murcia) and to explore the discriminative power of new, more specific markers. This is an essential step before addressing more complex epidemiological questions that can be crucial in improving management of $\mathrm{CA}$ in goats in endemic areas.

\section{Results}

\section{Strain typing by PFGE}

Four restriction endonucleases, SmaI, $M l u \mathrm{I}, K p n \mathrm{I}$ and BstZI, were selected that yielded easily interpretable PFGE banding patterns on our set of isolates. Their profiles clustered the 13 field isolates in 3 main groups A, B, C (Table 1), as illustrated by a representative gel in Figure 1. Group A included 6 of the 13 isolates, as well as the PG2 type strain. This group was very similar to the main European MA profile reported in 2008 by 
Table 2 Features of VNTRs Mycoplasma agalactiae isolates

\begin{tabular}{|c|c|c|c|c|c|c|}
\hline VNTR & Unit length (in nt) & Isolate & Copy number & Size (in nt) & Consensus sequence & Percentage of identity $^{a}$ \\
\hline \multirow[t]{3}{*}{5} & 21 & PG2 & 2.1 & 226 & AAAGAATATGA & $80-100 \%$ \\
\hline & & AG13 & 2.1 & 226 & TAAAATAAAA & \\
\hline & & AG28 & 2.1 & 228 & & \\
\hline \multirow[t]{2}{*}{14} & 13 & PG2 & 2 & 158 & TITAGATTGCTAA & $100 \%$ \\
\hline & & AG4 & 2 & 158 & & \\
\hline \multirow[t]{4}{*}{17} & 37 & PG2 & 2.6 & 209 & TATATACCTT & $86-100 \%$ \\
\hline & & AG30 & 4.4 & 285 & CTATTATTAC & \\
\hline & & AG32 & 6.3 & 337 & СТСТАТTAA & \\
\hline & & 5632 & 6.4 & 348 & TТACCTाT & \\
\hline \multirow[t]{2}{*}{19} & 21 & PG2 & 4.9 & 184 & TGTITCTTGC & $80-100 \%$ \\
\hline & & AG14 & 4.9 & 186 & TTCTTCTTGT & \\
\hline
\end{tabular}

${ }^{a}$ Proportion of sequence conserved between the strains examined.

McAuliffe et al. [9]. Interestingly, one isolate (AG18) yielded a pattern that differed slightly from that of the other members of the group. After SmaI digestion, it yielded the 6 characteristic fragments as well as a smaller one of $45 \mathrm{~kb}$ (Figure 1). Analysis with other endonucleases confirmed that this isolate appeared to have a genome that was larger than the other group A isolates by 40 to $50 \mathrm{~kb}$. Group B included all isolates from bulk tank milk (BTM) samples collected in Jumilla between the months of January and March 2000. These isolates appeared to be strictly clonal. Group $\mathrm{C}$ included two isolates from semen that were collected in 2008 from two different goat males in Lorca. No field strain had the same restriction pattern as the sequenced 5632 strain.

Previous PFGE analyses conducted on MA proved to discriminate poorly between local isolates from Italy [13] and, more recently, between isolates from all over Europe, all of each were found to be very similar to PG2 [9]. However, in the present study PFGE pulsotypes were not homogeneous, despite the restricted sampling area, and the three groups of strains appeared to be distinct with a discrimination index (D) of 0.73 according to Hunter and Gaston [20].

\section{Correlation between PFGE profiles and VNTR analyses}

Strains were subjected to VNTR analysis targeting 4 VNTRs, designated VNTR5, 14, 17, and 19, as previously described [9]. PCR results were first analysed by gel electrophoresis, which detected no difference between strains for VNTR5 or VNTR19, with all profiles identical, including those of the PG2 type strain and of 5632. While VNTR14 was of limited value as it only separated the strains into two groups, results obtained with VNTR 17 divided the 13 field isolates into 3 main clusters (TR2, TR3 and TR4) that matched the clusters obtained when comparing PFGE profiles (Table 1).
These data were further supported by comparing sequences of the PCR products obtained from representatives of the different VNTR profiles (Table 2). For this purpose, PCR products from (i) VNTR 5 of isolates AG13, AG28 and PG2, (ii) VNTR 14 of isolates AG4 and PG2 (iii) VNTR 17 of PG2 (P1), AG30 (P2), AG32 (P3) and 5632 (P4) (Figure 2), and (iv) VNTR 19 of AG14 and PG2 were directly sequenced (see Additional file 1: Table S1 for each VNTR sequence). Based on these sequence data, a consensus sequence was generated (Figure $2 \mathrm{C}$ for VNTR17) and the number of tandem repeats defined for each VNTR (Table 2). A VNTR profile, TR1 to TR5 (Table 1), was ascribed to each strain and the overall VNTR analysis found to match the PFGE clustering, although it did not discriminate strain AG18, which had a pulsotype slightly different from the overall group A. This is reflected by the index of discrimination which is slightly lower for VNTR typing (0.67) than for PFGE (0.73).

\section{Using the vpma profiles as a typing tool}

In MA, the vpma locus has been thoroughly studied and shown to encode genes with related sequences [15,2123]. The size of the vpma repertoire (number of vpma genes) varies between strains, but is constant within each strain. Here, we assessed the vpma profiles of our set of strains by Southern blot analyses using genomic DNA digested with AseI or AlwI and hybridised to different probes. The first probe was a single digoxigeninlabelled oligonucleotide probe, A3F, that detects the conserved $5^{\prime}$ ends of all vpma genes and thus assesses (when appropriate restriction endonucleases are used) the number of vpma genes in the strain, regardless of their specific vpma sequences. In contrast, the other 6 probes individually target each vpma gene found in the PG2 type strain (vpmaV to vpmaZ). Based on the 
(A)

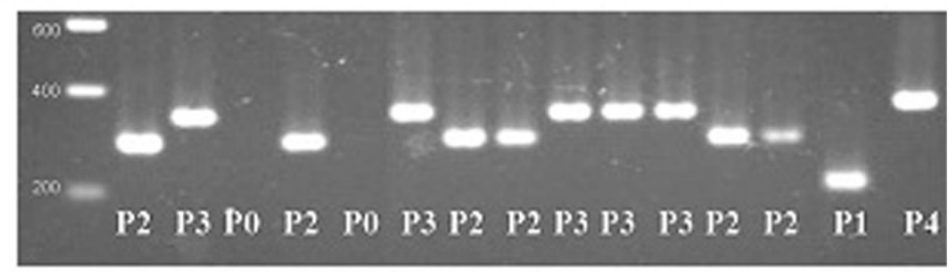

(B)

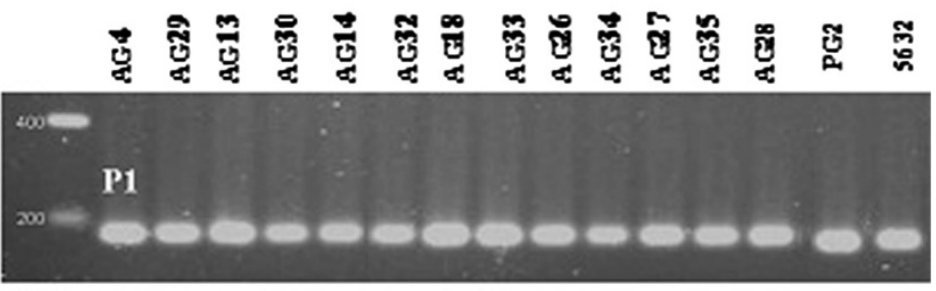

(C)

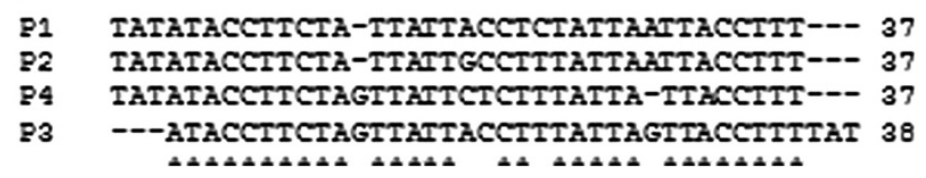

Figure 2 Profiles obtained with (A) VNTR 17, (B) VNTR 5 and (C) VNTR 17 nucleotide repeat sequences corresponding to PCR products of individual profile (P0 to P4). Positions with similar nucleotides in all profiles are marked with an asterisk. Isolates are indicated above the first gel. Lane 1, size marker (Smart Ladder Eurogentec).

hybridization results, a vpma profile was assigned to each strain (Table 1 and Additional file 2: Table S2 for detailed results).

As shown in Table 1, the vpma profiles were slightly more discriminative $(\mathrm{D}=0.74)$ than the VNTR or PFGE profiles because they divided the 13 isolates into 3 main groups, and differentiated AG18, AG13 and AG14 into different vpma subtypes. Strains of pulsotype A had vpma profiles similar to that of PG2 except for an additional hybridizing band in A3F that suggested the presence of an additional vpma gene in the Spanish strains in this group. All but AG18 also had a size difference in the fragment hybridizing to vpmaU compared to PG2. Strains in group B, as typed by PFGE, had an identical vpma profile that was clearly different from those of the other groups and from PG2 and 5632. Finally, the two strains isolated from semen (AG13 and 14) were also clustered using this approach and were clearly distinct from the other groups with a number of vpma differences, including the absence of bands hybridizing to $v p m a \mathrm{U}, \mathrm{V}, \mathrm{Y}$ or $\mathrm{Z}$ specific probes, together with a set of additional fragments hybridizing to the A3F probe. This suggested that isolates from semen possessed a different vpma repertoire from strains isolated from milk. These data correlated with those obtained with PFGE and VNTR.
Identification of potential new molecular typing tools

Based on the results obtained above, we assessed whether we could further divide the 3 main groups of Spanish isolates into subtypes. For this purpose, Southern blot analyses were first conducted using a set of 7 probes designated AGA/BOV that had been identified previously as specific for MA or Mycoplasma bovis but that had also been found to be subject to inter-strain variation within a species (Additional file 2: Table S2). AGA/BOV profiles (Table 1) correlated perfectly with the typing clusters obtained by PFGE and VNTR analyses, but had no additional power of discrimination $(\mathrm{D}=0.67)$.

Previous in silico comparative analysis indicated that 5632 and PG2 genomes differ by a number of genes, most of which fall into two categories: genes that are related to mobile genetic elements such as insertion sequences (IS) or integrative conjugative elements (ICE), and genes that encode enzymes of restriction modification systems [17]. Based on these data, PCR assays were then designed that either targeted the presence of a particular gene or the genomic location of particular elements (see Additional file 3: Table S3 and Additional file 4: Figure S1). A total of 20 PCR assays were performed on our set of isolates, and those with identical results were grouped (Table 1). PCR set 3 contained 6 PCR assays that yielded identical results with the isolates: no 
amplification from isolates in the $\mathrm{A}$ and $\mathrm{C}$ pulsotypes and amplification of a fragment of the expected size with isolates in the B and D pulsotypes. Since the assays in PCR set 3 mainly targeted mobile genetic elements such as IS or ICE, these data indicate that isolates from Yecla, Málaga and Lorca lack these mobile elements, clearly setting the Jumilla strains apart. Southern blot analyses further demonstrated the presence of the ICE only in the Jumilla isolates. The results obtained with PCR sets 3 and 6 are consistent with the grouping of the 13 isolates into 3 clusters, as with PFGE, VNTR and hybridization with $\mathrm{AGA} / \mathrm{BOV}$ probes assays. Isolate AG4 could be distinguished from the others with PCR set 5 (4 PCR assays). When combined, the PCR sets (or at least a combination of 3 : set 5 with set 2 or 3 and set 4 or 6$)$ were as discriminative as PFGE $(\mathrm{D}=0.73)$.

\section{Discussion}

In the present study, we assessed the use of validated and new approaches for the differentiation of caprine MA isolates collected from restricted geographical areas with endemic CA. Data showed that although the number of isolates included in our study was limited, their genetic content was surprisingly diverse when compared to the previous situation reported for sheep $[11,13,15]$. Thus, typing tools already validated with MA mostly isolated from ovine, such as VNTR or PFGE assays $[9,13,24]$, were shown to be also useful to discriminate MA collected in goats from a common geographical origin. This paves the way for addressing more complex epidemiological questions in the future. Our data also indicate that other molecular markers first used in this study would be worth evaluating on a larger scale, as they might increase the capacity to discriminate isolates with very similar profiles in PFGE or VNTR analyses. Where isolates cannot be distinguished by VNTR, the new assays offer alternative typing tools. Nevertheless, our data show that VNTR analyses using just VNTR17 is a powerful means of quickly discriminating goat MA isolates, even when they have been collected from a restricted endemic area.

The situation in Murcia (Spain) was ideal for this study because it has been known to have endemic CA for several decades $[18,19]$ and the dominance of a native goat breed in almost all herds limits the entry of animals from other areas of Spain. Although a larger number of isolates now need to be typed, data collected thus far is already informative because of the congruence of all typing techniques. They point to the circulation of two clonal groups, one in Yecla (profile A) and one in Jumilla (profile B), each with distinctive molecular features. The isolates from Yecla resemble the PG2 type strain, while isolates from Jumilla are rich in mobile genetic elements that are not found in PG2. This suggests a different origin of infection with no transfer between these two areas, which are only $28 \mathrm{~km}$ apart (see Additional file 5: Figure S2). The two semen isolates from the Lorca area, $150 \mathrm{kms}$ further South, gave almost identical profiles that differed from those collected from milk (in Lorca and other areas) as indicated by their vpma profiles and the presence of sequences coding for restriction modification systems (PCR set 4). Whether they represent clonal isolates is not known and there is certainly a need for detailed studies to determine whether isolates from semen form a true subgroup within MA. The prospect of associating a particular typing pattern with a particular tissue tropism is appealing but speculative at this time. To address this issue, more isolates collected in this area from semen and from milk or cases of mastitis would have to be analyzed.

In a recent study, a combination of genome-specific DNA probes and VNTRs indicated that CA in the Western Pyrenees region over the past 30 years has been caused by a unique subtype of MA [15]. This indicates that eradication programs implemented in the 1990s in this area, while efficient in reducing the prevalence of the disease, failed to eradicate the strain, which has reemerged over the last few years, causing significant economic losses. The situation encountered in the endemic area in Spain differs in that the genetic diversity of the circulating strains is high and that several strains appear to be present despite the restricted sampling area. This situation is likely to be the result of a long period of colonization and evolution, but raises the question of whether it is a characteristic of MA in goats or whether it may also occur in sheep. In goats, clinical signs are rare, and sporadic outbreaks are often related to the introduction of infected animals from other herds [4]. It has been suggested that the genetic diversity of MA might be linked to the importation of animals, with MA in self-sufficient countries having less genetic heterogeneity [10]. In the endemic area of Murcia, importation of goats is not common practice and thus is unlikely to be the reason for the genetic diversity of MA. The occurrence of asymptomatic auricular carriers in goat herds, with several mycoplasma species cohabiting in the ear canal raises the prospect of genetic exchange, which may contribute to the genetic variation seen in the Spanish isolates.

\section{Conclusions}

A number of typing tools are now available for the differentiation of goat MA isolates collected in restricted geographical areas with endemic CA. The genetic diversity of MA observed in infected goats in Spain contrasts with that seen in sheep with CA in southern France, suggesting that assessment of the disease status in 
endemic areas may require different approaches, depending on whether it involves goats or sheep.

\section{Methods}

Isolates and strains

A total of 13 field isolates were included in this study. They came from 3 main breeding areas (Jumilla, Yecla and Lorca) located in the goat-producing region of Murcia, Spain (see Additional file 5: Figure S2), a region known to have endemic CA $[18,19]$. They were isolated mainly from bulk tank milk (BTM) but two isolates were also obtained from the semen of 2 asymptomatic bucks (Table 1). One isolate from Málaga, a goat breeding area located further southwest, was also included. All these strains were analysed with strains PG2 and 5632, which were used as reference strains and have both been fully sequenced $[16,17]$.

\section{Culture and DNA extraction}

The isolates were identified as MA by both growth inhibition tests [25], dot immunoblotting on a filtration membrane (MF-dot) [26] and a species-specific PCR [11]. All strains were cultured in SP4 broth at $37^{\circ} \mathrm{C}$ [27]. Genomic DNA was extracted with chloroform using standard procedures [28].

\section{Pulsed field gel electrophoresis (PFGE)}

Agarose plugs containing mycoplasma DNA were prepared as described previously [29]. They were incubated in $0.1 \%$ Triton X-100 for 2 hours at $4^{\circ} \mathrm{C}$ before digestion with restriction endonucleases overnight at $37^{\circ} \mathrm{C}$ using 50 units of either SmaI, MluI, BstZI and KpnI (Promega, Charbonnières-les-Bains, France). Electrophoresis was performed using the CHEF-Mapper system (Bio-Rad, Marnes-la-Coquette, France) with the standard $\lambda$ concatamer ladder (Bio-Rad) as a molecular size marker. Agarose gels (1\%) were run in $0.5 \mathrm{X} \mathrm{TBE}$ at $14^{\circ} \mathrm{C}$, at a field strength of $6 \mathrm{~V} / \mathrm{cm}$, over $24 \mathrm{~h}$ with an included angle of $120^{\circ}$, and the pulse time ramped linearly from 10 to 60 seconds. Gels were stained with ethidium bromide and visualized using the Gel-Doc 2000 image analysis system (Bio-Rad).

\section{Variable number of tandem repeats (VNTR)}

VNTR analyses were performed as described previously $[9,15]$. Briefly, PCR assays were conducted in a Mastercycler ep-Gradient thermocycler (Eppendorf, Le Pecq, France) in a total volume of $25 \mu$ l containing $0.4 \mathrm{mM}$ of each primer, 1 X PCR buffer (with $\mathrm{MgSO}_{4}$; New England Biolabs, Ipswich, MA, USA), $200 \mathrm{mM}$ of each deoxynucleoside triphosphate and 2 units of Taq DNA polymerase (New England Biolabs). The PCR thermal program consisted of $5 \mathrm{~min}$ at $94^{\circ} \mathrm{C}$, followed by 30 cycles of $1 \mathrm{~min}$ at $94^{\circ} \mathrm{C}, 45 \mathrm{~s}$ at $56^{\circ} \mathrm{C}$ and $1 \mathrm{~min}$ at $72^{\circ} \mathrm{C}$, and a final extension step for $10 \mathrm{~min}$ at $72^{\circ} \mathrm{C}$. The PCR amplification products were analysed by gel electrophoresis on $2.5 \%(\mathrm{w} / \mathrm{v})$ agarose gels and visualised, after staining with ethidium bromide using, a UV transilluminator.

For each VNTR, one PCR product representative of each distinct profile was sequenced. The product obtained from the type strain PG2 was also sequenced. The PCR products were purified using the QIAquick PCR Purification kit (Qiagen, Alameda, CA, USA) and then sequenced by IF30, CHU Purpan, University of Toulouse (France). Tandem repeats in each sequence were identified using the on-line tandem repeat finder program at http://tandem.bu.edu/trf/trf.html. The data obtained were then compared using Needle at http:// www.ebi.ac.uk/Tools/emboss/align/ and ClustalW2 at http://www.ebi.ac.uk/Tools/clustalw2/ to determine the consensus sequence for each VNTR, and the number of repeats in each product. Finally, strains were classified according to the size of the fragment and number of repeats.

\section{Southern blots}

Several probes were used to examine genetic variability in strains of MA. The repertoires of vpma loci in the isolates were determined using 6 individual probes based on the PG2 sequence, and the general probe A3F $[21,22]$. Profiles were also obtained using a set of 7 AGA and $\mathrm{BOV}$ probes, previously shown to discriminate MA isolates from diverse origins [11]. In addition, the presence and number of ICEs in the genome was determined using Digoxigenin-labelled probes for ICEA ${ }_{5632}$ (CDS1, CDS5 and CDS22) [11,15,17]. Approximately $1 \mu \mathrm{g}$ of genomic DNA was digested with HindIII, EcoRI (Promega Laboratories), AseI or AlwI (New England Biolabs), subjected to $1 \%$ agarose gel electrophoresis and transferred onto nylon membranes (Roche, Indianapolis, IN, USA). Specific probes for each of the six vpma genes in PG2 (vpmaU, vpmaV, vpmaW, vpmaX, vpmaY and vpmaZ) were labelled with Digoxigenin-11-dUTP (Roche) by PCR, as described previously [21]. The probes AGA and BOV used in this study were prepared by PCR as described previously [11].

In all cases, after a denaturation step of $100^{\circ} \mathrm{C}$, probes and membranes were incubated in Church buffer [30] overnight at $55^{\circ} \mathrm{C}$. The membranes were then briefly washed in $0.2 \times \mathrm{SSC} / 0.1 \% \mathrm{SDS}$ at room temperature and then in $0.2 \times \mathrm{SSC} / 0.1 \% \mathrm{SDS}$ for $1 \mathrm{~h}$ at $55^{\circ} \mathrm{C}$. The oligonucleotide probe A3F, (5' - AA(A/G)TG(T/C)GG(A/T) GG(A/T)AC(A/T)A(A/C)(A/T)(A/G)A-3') [15,22] was incubated with the membranes overnight at $45^{\circ} \mathrm{C}$ and two washing steps were then conducted in $6 \times \mathrm{SSC} / 0.1 \%$ SDS for $10 \mathrm{~min}$ each at $45^{\circ} \mathrm{C}$. In all cases, hybridized probes were detected with alkaline phosphatase- 
conjugated anti-Dig Fab antibodies and CDPstar reagents (Roche).

\section{Identification of new PCR assays as typing tools}

Several PCR assays (see Additional file 3: Table S3) were performed to explore differences between the strains on the basis of previously observed differences between PG2 and 5632 and on in silico comparison of their genomic se quences $[16,17]$. Further specific PCR assays were conducted. When necessary, primers were designed using the on-line program Primer3Plus at http://www. bioinformatics. nl / cgi-bin / primer3plus / primer3plus .cgi (see Additional file 6: Table S4). All PCRs were performed as described for the VNTR analysis by incubation for $2 \mathrm{~min}$ at $94^{\circ} \mathrm{C}$, followed by 30 cycles of $30 \mathrm{~s}$ at $94^{\circ} \mathrm{C} / 30 \mathrm{~s}$ at the appropriate melting temperature (see Additional file 3: Table S3) and $30 \mathrm{~s}$ at $72^{\circ} \mathrm{C}$, and then by a final extension step of $5 \mathrm{~min}$ at $72^{\circ} \mathrm{C}$. PCR products were analysed by electrophoresis in $1 \%$ agarose gels.

\section{Additional files}

Additional file 1: Table S1. VNTR nucleotide sequences.

Additional file 2: Table S2. Profiles obtained with the probe A3F, the set of individual Vpma probes and the AGA-BOV probes used in this study.

Additional file 3: Table S3. Description of additional PCRs conducted in this study, the results of which are summarized in Table 1.

Additional file 4: Figure S1. Illustration of some genomic differences between M. agalactiae strains PG2 and 5632 that were used to design new PCR typing assays.

Additional file 5: Figure S2. Geographic origin of Mycoplasma agalactiae isolates.

Additional file 6: Table S4. Primer sequences.

\section{Competing interests}

The authors declare that they have no competing interests.

\section{Authors' contributions}

CDF conceived the study, carried out part of the genomic studies, participated in its design and drafted the manuscript. JA carried out the PFGE genomic studies and drafted the manuscript. FT participated in the design and the coordination of the study, contributed to PFGE studies and drafted the manuscript. ES carried out part of the genomic studies. LXN participated in study design and coordination, and drafted the manuscript. CC conceived the study, participated in its design and coordination, and drafted the manuscript. All authors read and approved the manuscript.

\section{Acknowledgements}

The travel fellowship (2009) of C. De la Fe at the UMR 1225 INRA-Ecole National Vétérinaire de Toulouse, France, was granted by the Fundación Séneca, Agencia de Ciencia y Tecnología de la Región de Murcia, Spain (Ref. 11662/EE2/09, II PCTRM 2007-2010). The travel fellowship of J. Amores at Anses in the laboratory of Lyon, France, was also funded by an FPI grant of the Ministerio de Educación y Ciencia, Spain. This study was partially supported by the projects AGL2009-09128 and Fundación Séneca $11785 / \mathrm{Pl} / 09$. Part of the work described in this manuscript was conducted by J. Amores for his PhD thesis.

\section{Author details}

'Departamento de Sanidad Animal, Facultad de Veterinaria, Universidad de Murcia, Campus de Espinardo s/n, 30100 Murcia, Spain. ${ }^{2}$ UMR

Mycoplasmoses des Ruminants, Anses, Laboratoire de Lyon, 31 Avenue Tony Garnier, 69364 Lyon Cedex 07, France. ${ }^{3}$ INRA, UMR 1225, Ecole Nationale Vétérinaire de Toulouse, 23 Chemin des Capelles, 31076 Toulouse Cedex 3, France. ${ }^{4}$ Université de Toulouse, INP-ENVT, UMR 1225, Ecole Nationale Vétérinaire de Toulouse, 23 Chemin des Capelles, 31076 Toulouse Cedex 3, France.

Received: 9 September 2011 Accepted: 14 August 2012

Published: 27 August 2012

\section{References}

1. Bergonier D, Berthelot $X$, Poumarat P: Contagious agalactia of small ruminants: current knowledge concerning epidemiology, diagnosis and control. Rev Sci Tech 1997, 16:848-873.

2. Al-Momani W, Nicholas RA, Abo-Shehada MN: Risk factors associated with Mycoplasma agalactiae infection of small ruminants in northern Jordan. Prev Vet Med 2008, 83:1-10.

3. Sanchis R, Abadie G, Lambert M, Cabasse E, Dufour P, Guibert JM, Pepin M Inoculation of lactating ewes by the intramammary route with Mycoplasma agalactiae: comparative pathogenicity of six field strains. Vet Res 2000, 31:329-337.

4. Corrales JC, Esnal A, De la Fe C, Sánchez A, Assuncão P, Poveda JB, Contreras A: Contagious agalactia in small ruminants. Small Rumin Res 2007, 68:154-166.

5. Gil MC, Hermoso de Mendoza M, Rey J, Alonso JM, Poveda JB, Hermoso de Mendoza J: Isolation of mycoplasmas from the external ear canal of goats affected with contagious agalactia. Vet J 1999, 158:152-154.

6. De la Fe C, Assuncão P, Rosales RS, Antunes T, Poveda JB: Microbiological study of contagious agalactia in a serological endemic area. Vet J 2005, 170:257-259.

7. Mercier P, Pellet M, Morignat E, Calavas D, Poumarat F: Prevalence of mycoplasmas in external ear canal of goats: Influence of the sanitary status of the herd. Small Rumin Res 2007, 73:296-299.

8. Tardy F, Mercier P, Solsona M, Saras E, Poumarat F: Mycoplasma mycoides subsp. mycoides biotype large colony isolates from healthy and diseased goats: prevalence and typing. Vet Microbio/ 2007, 121:268-277.

9. McAuliffe L, Churchward CP, Lawes JR, Loria G, Ayling RD, Nicholas RA: VNTR analysis reveals unexpected genetic diversity within Mycoplasma agalactiae, the main causative agent of contagious agalactia. BMC Microbiol 2008, 8:193

10. McAuliffe L, Gosney F, Hlusek M, de Garnica ML, Spergser J, Kargl M, Rosengarten R, Ayling RD, Nicholas RA, Ellis RJ: Multilocus sequence typing of Mycoplasma agalactiae. J Med Microbiol 2011, 6:803-811.

11. Marenda MS, Sagne E, Poumarat F, Citti C: Suppression subtractive hybridization as a basis to assess Mycoplasma agalactiae and Mycoplasma bovis genomic diversity and species-specific sequences. Microbiology 2005, 151:475-489.

12. Pilo P, Fleury B, Marenda M, Frey J, Vilei EM: Prevalence and distribution of the insertion element ISMag1 in Mycoplasma agalactiae. Vet Microbiol 2003, 92:37-48.

13. Tola S, Idini G, Manunta D, Casciano I, Rocchigiani AM, Angioi A, Leori G: Comparison of Mycoplasma agalactiae isolates by pulsed field gel electrophoresis, SDS-PAGE and immunoblotting. FEMS Microbio/ Lett 1996, 143:259-265.

14. Solsona M, Lambert M, Poumarat F: Genomic, protein homogeneity and antigenic variability of Mycoplasma agalactiae. Vet Microbiol 1996, 50:45-58.

15. Nouvel LX, Marenda MS, Glew MD, Sagné E, Giammarinaro P, Tardy F, Poumarat F, Rosengarten R, Citti C: Molecular typing of Mycoplasma agalactiae: Tracing European-wide genetic diversity and an endemic clonal population. Comp Immunol Microbiol Infect Dis 2012, 35:487-496.

16. Sirand-Pugnet $P$, Lartigue $C$, Marenda M, Jacob D, Barre A, Barbe V, Schenowitz C, Mangenot S, Couloux A, Segurens B, de Daruvar A, Blanchard A, Citti C: Being pathogenic, plastic, and sexual while living with a nearly minimal bacterial genome. PLoS Genet 2007, 3:e75.

17. Nouvel LX, Sirand-Pugnet $P$, Marenda MS, Sagné E, Barbe V, Mangenot $S$, Schenowitz C, Jacob D, Barré A, Claverol S, Blanchard A, Citti C: Comparative genomic and proteomic analyses of two Mycoplasma 
agalactiae strains: clues to the macro- and micro-events that are shaping mycoplasma diversity. BMC Genomics 2010, 11:86.

18. Contreras A, Corrales JC, Sierra D, Marco J: Prevalence and aetiology of non-clinical intramammary infection in Murciano-Granadina goats. Small Rum Res 1995, 17:71-78.

19. Contreras A, Miranda RE, Sánchez A, De la Fe C, Sierra D, Luengo C, Corrales JC: Presence of Mycoplasma species and somatic cell counts in bulk-tank milk. Small Rum Res 2008, 75:247-251.

20. Hunter PR, Gaston MA: Numerical index of the discriminatory ability of typing systems: an application of Simpson's index of diversity. J Clin Microbiol 1988, 26:2465-2466

21. Glew MD, Marenda M, Rosengarten R, Citti C: Surface diversity in Mycoplasma agalactiae is driven by site-specific DNA inversions within the vpma multigene locus. J Bacteriol 2002, 184:5987-5998.

22. Glew MD, Marenda M, Bergonier D, Rosengarten R, Citti C: The vpma gene repertoires in Mycoplasma agalactiae. In Mycoplasmas of ruminants: pathogenicity, diagnostics, epidemiology and molecular genetics. Volume 5. Edited by Poveda JB, Fernández A, Frey J, Johansson K.: Office for Official Publications of the European Communities. COST Action 826 - EUR 19693; 2001:18-21.

23. Nouvel LX, Marenda M, Sirand-Pugnet $P$, Sagné E, Glew M, Mangenot $S$, Barbe V, Barré A, Claverol S, Citti C: Occurrence, plasticity, and evolution of the vpma gene family, a genetic system devoted to high-frequency surface variation in Mycoplasma agalactiae. J Bacteriol 2009, 191:4111-4121.

24. Tola S, Idini G, Rocchigiani M, Manunta D, Angioi PP, Rocca S, Cocco M, Leori G: Comparison of restriction pattern polymorphism of Mycoplasma agalactiae and Mycoplasma bovis by pulsed field gel electrophoresis. J Med Vet B 1999, 46:199-206.

25. Poveda JB, Nicholas R: Serological identification of mycoplasmas by growth and metabolic inhibition tests. In Methods in Molecular Biology: Vol. 104 Mycoplasma Protocols. Edited by Miles R, Nicholas RAJ. Totowa: Humana Press; 1998:105-111.

26. Poumarat F: Identification of mycoplasmas by dot immunobinding on membrane filtration (MF-Dot). Methods Mol Biol 1998, 104:113-118.

27. Tully JG: Culture medium formulation for primary isolation and maintenance of mollicutes. In Molecular and Diagnostic Procedures in Mycoplasmology: Molecular Characterization. Edited by Tully JG. San Diego: Academic Press; 1995:33-39.

28. Chen WP, Kuo T: A simple and rapid method for the preparation of gram-negative bacterial genomic DNA. Nucleic Acids Res 1993, 21:2260.

29. Ladefoged S, Christiansen G: Physical and genetic mapping of the genomes of five Mycoplasma hominis strains by pulsed field ge electrophoresis. J Bacteriol 1992, 174:2199-2207.

30. Church GM, Gilbert W: Genomic sequencing. Proc Natl Acad Sci USA 1984, 81:1991-1995.

doi:10.1186/1746-6148-8-146

Cite this article as: De la Fe et al.: Unexpected genetic diversity of Mycoplasma agalactiae caprine isolates from an endemic geographically restricted area of Spain. BMC Veterinary Research 2012 8:146.

\section{Submit your next manuscript to BioMed Central and take full advantage of:}

- Convenient online submission

- Thorough peer review

- No space constraints or color figure charges

- Immediate publication on acceptance

- Inclusion in PubMed, CAS, Scopus and Google Scholar

- Research which is freely available for redistribution 